\title{
ASSOCIATION BETWEEN SUGAR-SWEETENED BEVERAGE CONSUMPTION AND BODY MASS INDEX AMONG UNIVERSITY STUDENTS IN KUALA NERUS, TERENGGANU, MALAYSIA
}

\author{
Aida Aliah Abu Bakar ${ }^{1},{ }^{*}$ Napisah Hussin ${ }^{1}$, Abbe Maleyki Mhd. Jalil ${ }^{1}$ and Marhazlina Mohamad ${ }^{1}$ \\ ${ }^{1}$ School of Nutrition and Dietetics, Faculty of Health Sciences, Universiti Sultan Zainal Abidin, Kuala Nerus, Terengganu, \\ Malaysia
}

Corresponding author: Napisah Hussin

Email: napisah@unisza.edu.my

\begin{abstract}
Overweight and obesity are major health concerns in Malaysia, which are linked to other health consequences such as type 2 diabetes mellitus, cardiovascular diseases and several others. Among dietary factors, sugar-sweetened beverages (SSBs) are reported to be one of the leading factors of weight gain and a higher body mass index (BMI). Sugar-sweetened beverages are beverages with added sugar that only add calories to an individual's normal diet and they represent the largest contributor to the added sugars intake. This study was aimed to determine the prevalence of SSB consumption among university students in Kuala Nerus, Terengganu, as well as to investigate the association between the students' SSB consumption and their BMI. A cross-sectional study was conducted among 350 Universiti Sultan Zainal Abidin (UniSZA) Gong Badak Campus and Universiti Malaysia Terengganu (UMT) students by using the convenience sampling. Each participant was given a questionnaire consisting of socio-demographic details, anthropometric assessment and beverage intake. The results revealed that half of the students consumed 2 cups (500 $\mathrm{mL}$ ) of SSBs on average days (49.4\%), whereas $21.7 \%$ of them consumed at least 3 cups daily. It was found that sweetened tea was the students' most preferred SSB and there was also an association between the SSB consumption and the BMI. In conclusion, university students in Kuala Nerus drink 2 cups of SSBs daily and sweetened tea is their preferred SSB. Since the students' SSB consumption influences their BMI, these students must be aware on the contents of SSB and the related health consequences in order to reduce the consumption of these beverages and hence, reduce their $B M I$ to a healthy level.
\end{abstract}

Keywords: Sugar-sweetened beverages, Consumption, Body weight, BMI, Sugar

\section{INTRODUCTION}

One of the major health concerns in Malaysia is overweight and obesity, as well as the health consequences associated with these conditions ${ }^{1}$. According to World Health Organization ${ }^{2}$, there were $29 \%$ of the Malaysian population who were overweight and $15 \%$ of them were obese. A related finding from the Malaysian National Health and Morbidity Survey ${ }^{3}$ estimated that 5.6 million adults, ages 18 and above, were overweight, whereas 3.3 million were obese. According to a report, it was stated that among many dietary determinants of obesity, sugarsweetened beverage consumption such as soft drinks, is one of the factors leading to overweight and obesity among the Malaysian population ${ }^{4}$. On top of that, these beverages can also be associated with diabetes, metabolic syndrome, cardiovascular risk factors and elevated blood pressure ${ }^{5}$. Besides, Martin-Calvo et $\mathrm{al}^{6}$ has found that there is a positive association between sugarsweetened beverage consumption and increased body weight, thus increased body mass index (BMI). Sugar-sweetened beverages (SSBs) are available in many forms can be served however the consumer prefers. What causes an alarming rate of increased childhood obesity worldwide is that these drinks are available almost anywhere and they are sold at an incredibly cheap price which encourages university students to be able to pay for a drink at least once a day. This has shown that the production of SSBs is easily attainable and without control over these beverages intake, it may lead to increased weight gain thus increased BMI.

Another factor which contributes to a higher rate of sugar-sweetened beverage consumption is sociability. Nanney et $\mathrm{al}^{7}$ has shown that most of the respondents in this particular study were young people, especially school children and university students. Thus, this explains why SSBs are often consumed by the younger generation as they do so to socialize with their peers. Besides, children and adolescents often have the tendency to consume soft drinks when their peers do. There were studies which had shown that soft drink consumption among students was mainly influenced by their peers, as they tend to socialize themselves among others ${ }^{8,9}$. It was reported that university students generally tend to engage in problematic eating behaviours, including unhealthy dieting, skipping meals and high intake of fast food, although they are aware of the negative consequences ${ }^{10}$. Mahmood et al. ${ }^{11}$ 
and Munt et al. ${ }^{12}$ reported that enjoying the taste of SSBs is identified as another reason for its consumption. However, many studies regarding SSB consumption and its link to health have been carried out in state of Selangor, Malaysia with its respondents of mainly school-aged children. Furthermore, not many studies have identified the SSB consumption pattern among university students from other states that may have different availability of SSBs and interventions that could address the growing rate of obesity in Malaysia. Thus, in order to develop effective strategies to tackle this issue, this study determines the pattern of SSB consumption and its association with BMI among university students in Kuala Nerus, Terengganu, Malaysia.

\section{METHODS}

\section{Population and setting}

A cross-sectional study was conducted from January to March 2019 to achieve the aims of the study. This study was conducted among 350 students from Universiti Sultan Zainal Abidin (UniSZA) Gong Badak Campus and Universiti Malaysia Terengganu (UMT). The ethical approval was granted by the UniSZA Human Research Ethics Committee (UHREC) [UniSZA.C/2/UHREC/628$2(61)$ ] prior to study commencement. Any information given by the participant was strictly for the purpose of the study and confidential.

\section{Inclusion and Exclusion Criteria}

The participants were selected by convenience sampling and were screened for the inclusion and exclusion criteria. Participants selected must be at least 18 years old, attending UniSZA Gong Badak campus and UMT and able to understand English. The exclusion criteria were students which undergoing any dietary intervention, pregnant and lactating mothers, with amputee or wheelchair-bound and taking any medication that could interfere with their normal drink consumption pattern.

\section{Research Instruments}

A set of questionnaires consisting of three (3) components; socio-demographic details, anthropometric assessment and beverage intake. Prior to be disseminated to the respondents, a pilot study was performed among 30 UniSZA students in order to validate and examine the reliability of the modified beverage intake questionnaire which was previously developed by Hedrick et al. ${ }^{13}$. Cronbach's alpha Coefficient was used to determine the internal consistency (0.743). Socio-demographic details consisted information on the participants' age, gender, ethnicity, educational level and financial status. The weight of the subjects was measured in kilograms (kg) using Seca Clara 803 Electronic Weighing Scale. During the measuring of weight, all respondents were asked to wear minimal amount of clothing. Personal accessories such as watch, ring, wallet, keys, shoes, socks, and any other object that could interfere with the accurate reading of weight, were taken off before the assessment. The height of the subjects was measured in centimetres $(\mathrm{cm})$ using Seca 213 Portable Stadiometer. During the measuring of height, all subjects were asked to take off their shoes and socks, stand up straight with back pressed against the wall, beneath the stadiometer. Subjects should be facing straight ahead, with eye level parallel to the floor, with their arms at the sides. Both instruments were calibrated before each session. All measurements were taken three times and averaged.

Body Mass Index (BMI) was calculated using the formula $=($ weight in $\mathrm{kg}) /(\text { height in } \mathrm{m})^{2}$. Each reading was then categorized under four main categories which are underweight (less than 18.5 $\left.\mathrm{kg} / \mathrm{m}^{2}\right)$, normal weight $\left(18.5-24.9 \mathrm{~kg} / \mathrm{m}^{2}\right)$, overweight $\left(25.0-29.9 \mathrm{~kg} / \mathrm{m}^{2}\right)$, and obese $(30.0$ $\mathrm{kg} / \mathrm{m}^{2}$ and more), according to WHO cut-off points ${ }^{14}$. The questionnaire for SSB intake includes items such as intake and frequency of several types of beverages. The questionnaire used in this study has been adapted from a questionnaire developed by Hedrick et al. ${ }^{13}$ and was modified according to the availability of beverages in Malaysia. Beverages included in the list of SSBs in this study are sweetened fruit juice, whole milk, reduced fat milk, low fat milk, regular soft drinks, sweetened tea and coffee, energy or sports drinks, meal replacement or protein shakes, fermented drinks, and stall drinks that do not include the beverages mentioned previously (such as sirap bandung, teh ais limau, etc). SSB consumption was then categorised into three (3) coding according to the number of cups measured in millimetres $(\mathrm{mL})$ consumed per day that are low ( $\leq 250 \mathrm{ml} / \mathrm{d})$, moderate $(500 \mathrm{ml} / \mathrm{d})$ and high consumption ( $\geq 750 \mathrm{ml} / \mathrm{d})$. Participants were required to complete the questionnaire according to their usual beverage intake on the average days.

\section{Statistical Analysis}

The statistical analysis of data was performed using IBM SPSS software for Windows, version 21.0. Statistical significance of all tests was set at the level of $p \leq 0.05$ and each test was done according to the objectives of the study. The socio-demographic details were tested using descriptive statistics and also Independent $t$-test to determine mean, standard deviation, and $\mathrm{p}$ value, whereas the relationship between SSB consumption and BMI was tested by Chi-square test.

\section{RESULTS}

A total number of 350 students participated in this study, where majority were female (70.6\%), within the age range of 21 to 30 years old $(77.1 \%)$ and Malay (75.1\%). There were $53.4 \%$ of students represented UniSZA and most of them were in the degree level (84.6\%). 
Malaysian Journal of Public Health Medicine 2020, Vol. 20 (2): 19-26

Table 1: Students' socio-demographic details $(n=350)$

\begin{tabular}{|c|c|c|}
\hline Characteristics & $\mathbf{n}$ & $\%$ \\
\hline \multicolumn{3}{|l|}{ Gender } \\
\hline Male & 103 & 29.4 \\
\hline Female & 247 & 70.6 \\
\hline \multicolumn{3}{|l|}{ Age } \\
\hline$\leq 20$ years old & 80 & 22.9 \\
\hline $21-30$ years old & 270 & 77.1 \\
\hline \multicolumn{3}{|l|}{ Ethnicity } \\
\hline Malay & 263 & 75.1 \\
\hline Chinese & 37 & 10.6 \\
\hline Indian & 29 & 8.3 \\
\hline Others & 21 & 6.0 \\
\hline \multicolumn{3}{|l|}{ University } \\
\hline UniSZA & 187 & 53.4 \\
\hline UMT & 163 & 46.6 \\
\hline \multicolumn{3}{|l|}{ Level of Study } \\
\hline Diploma & 51 & 14.6 \\
\hline Degree & 296 & 84.6 \\
\hline Masters & 3 & 0.9 \\
\hline \multicolumn{3}{|l|}{ Total Family Income (monthly) } \\
\hline$<$ RM 5,000 & 154 & 44.0 \\
\hline RM 5,000 - RM 9,999 & 131 & 37.4 \\
\hline$\geq$ RM 10,000 & 65 & 18.6 \\
\hline \multicolumn{3}{|l|}{ Study Financial } \\
\hline PTPTN & 151 & 43.1 \\
\hline MARA/JPA & 109 & 31.1 \\
\hline None & 64 & 18.3 \\
\hline Others & 26 & 7.4 \\
\hline \multicolumn{3}{|c|}{ Financial Support From Other Family Member } \\
\hline Yes & 177 & 50.6 \\
\hline No & 173 & 49.4 \\
\hline
\end{tabular}

\section{Anthropometric Assessment}

Tables 2 and 3 summarise the anthropometric assessments of students in which $56.6 \%$ of students had normal BMI and there was a significant difference in BMI between male and female students $(p<0.05)$.

Table 2: Anthropometric assessment among students $(\mathrm{n}=350)$

\begin{tabular}{|c|c|c|c|c|c|}
\hline \multirow{2}{*}{$\begin{array}{l}\text { Anthropometric } \\
\text { assessment }\end{array}$} & \multicolumn{2}{|c|}{ Mean (SD) } & \multirow{2}{*}{$\begin{array}{c}\text { Total } \\
(\text { mean } \pm S D)\end{array}$} & \multirow{2}{*}{$\begin{array}{c}\text { Mean } \\
\text { difference } \\
(95 \% \mathrm{Cl})\end{array}$} & \multirow{2}{*}{$\begin{array}{c}\text { P- } \\
\text { value }^{a}\end{array}$} \\
\hline & $\begin{array}{c}\text { Male } \\
n=103\end{array}$ & $\begin{array}{c}\text { Female, } \\
n=247\end{array}$ & & & \\
\hline Height (m) & $1.70(0.05)$ & $1.57(0.05)$ & $1.61 \pm 0.08$ & $\begin{array}{c}1.63 \\
(1.41,1.85)\end{array}$ & 0.274 \\
\hline Weight (kg) & $64.30(11.38)$ & $55.44(11.76)$ & $58.05 \pm 12.32$ & $\begin{array}{c}75.50 \\
(36.00,115.00)\end{array}$ & 0.279 \\
\hline BMI $\left(\mathrm{kg} / \mathrm{m}^{2}\right)$ & $22.20(3.37)$ & $22.35(4.56)$ & $22.31 \pm 4.24$ & $\begin{array}{c}25.25 \\
(14.50,36.00)\end{array}$ & $0.001^{*}$ \\
\hline
\end{tabular}

andependent $t$-test was applied.

*Significant difference between genders at $p<0.05$

Table 3: Body Mass Index classification of students $(n=350)$ 
Malaysian Journal of Public Health Medicine 2020, Vol. 20 (2): 19-26

\begin{tabular}{lllll}
\hline & Body Mass Index & Male & Female \\
$\mathbf{n}(\%)$ & $\begin{array}{l}\text { Total } \\
\mathbf{n}(\%)\end{array}$ \\
\hline Classification & $\begin{array}{l}\text { Cut-off point } \\
\left(\mathrm{kg} / \mathrm{m}^{2}\right)\end{array}$ & $\mathbf{n}(\%)$ & $50(20.2)$ & $61(17.4)$ \\
\hline Underweight & $<18.5$ & $68(66.0)$ & $130(52.6)$ & $198(56.6)$ \\
Normal & $18.5-24.9$ & $21(20.4)$ & $47(19.0)$ & $68(19.4)$ \\
Overweight & $25.0-29.9$ & $3(2.9)$ & $20(8.1)$ & $23(6.6)$ \\
Obese & $\geq 30.0$ & &
\end{tabular}

aBMI cut-off points according to WHO (2004) ${ }^{14}$

\section{Sweetened Sugar Beverage Intake}

Table 4 shows that the female students' intake of plain water, low fat milk and fermented drinks were significantly higher than male students whereas male students' intakes of regular soft drinks, sweetened coffee, unsweetened tea/coffee, and energy/sports drink were significantly higher than females. Regardless of genders, sweetened tea appeared to be their preferred SSB. Low fat milk and fermented drinks are considered especially by female students as healthy beverages in the market that provides them with positive health benefits. They tend to believe that consuming lower fat milk can provide the benefits of milk and supplying less fat while yogurt and fermented beverage can be a useful source of protein on a weight-loss diet.

Table 4: Daily beverage intake of students $(n=350)$

\begin{tabular}{|c|c|c|c|}
\hline \multirow[t]{2}{*}{ Type of Beverages } & \multicolumn{2}{|c|}{$\begin{array}{c}\text { Mean (SD) } \\
\text { mL/day }\end{array}$} & \multirow[t]{2}{*}{ P-value $^{a}$} \\
\hline & Male & Female & \\
\hline Plain water & $979.54(443.37)$ & $1,111.16(490.89)$ & $0.019^{*}$ \\
\hline $100 \%$ Fruit Juice & $22.80(57.40)$ & $28.92(99.64)$ & 0.560 \\
\hline Sweetened Juice Drink & 44.64 (63.69) & 61.99 (156.24) & 0.277 \\
\hline 100\% Vegetable Juice & $9.80(19.83)$ & $9.04(23.27)$ & 0.772 \\
\hline Whole Milk & $44.30(88.40)$ & $70.81(137.51)$ & 0.072 \\
\hline Reduced Fat Milk (2\%) & $8.84(40.10)$ & $20.23(124.79)$ & 0.362 \\
\hline $\begin{array}{l}\text { Low Fat / Fat Free Milk (Skim, 1\%, } \\
\text { Soymilk) }\end{array}$ & $24.97(82.90)$ & $60.62(140.40)$ & $0.017^{*}$ \\
\hline Soft Drinks, Regular & $87.12(236.82)$ & $29.89(65.42)$ & $0.017^{*}$ \\
\hline $\begin{array}{l}\text { Diet Soft Drinks / Artificially Sweetened } \\
\text { Drinks }\end{array}$ & $13.70(82.67)$ & $11.78(30.69)$ & 0.753 \\
\hline Sweetened Tea, with sugar and/or milk & $116.68(238.59)$ & $124.31(185.85)$ & 0.748 \\
\hline $\begin{array}{l}\text { Sweetened Coffee, with cream and/or } \\
\text { sugar }\end{array}$ & $98.30(113.20)$ & $57.44(145.75)$ & $0.011^{*}$ \\
\hline $\begin{array}{l}\text { Tea / Coffee, black (no sugar / milk / } \\
\text { cream) }\end{array}$ & $41.52(60.89)$ & $21.65(49.43)$ & $0.004^{*}$ \\
\hline Energy \& Sports Drinks & $33.55(50.78)$ & $7.01(18.98)$ & $<0.001^{*}$ \\
\hline Meal Replacement / Protein Shakes & $8.50(32.15)$ & $8.13(26.05)$ & 0.912 \\
\hline Fermented Drinks & $20.46(32.76)$ & $34.23(41.12)$ & $0.003^{*}$ \\
\hline Stall Drinks & $73.16(107.31)$ & $87.01(148.71)$ & 0.392 \\
\hline
\end{tabular}

andependent $t$-test was applied.

*Significant difference between genders at $p<0.05$

\section{Pattern of SSB Consumption}

Figure 1 shows the pattern of SSB consumption consumption and students' BMI categories, with $\mathrm{p}$ among students on the average days. Almost half of the students $(49.4 \%)$ consumed moderate amounts of SSB, which most likely be due to its vast availability on campus and its cheap price.

$$
=0.014 \text {. }
$$




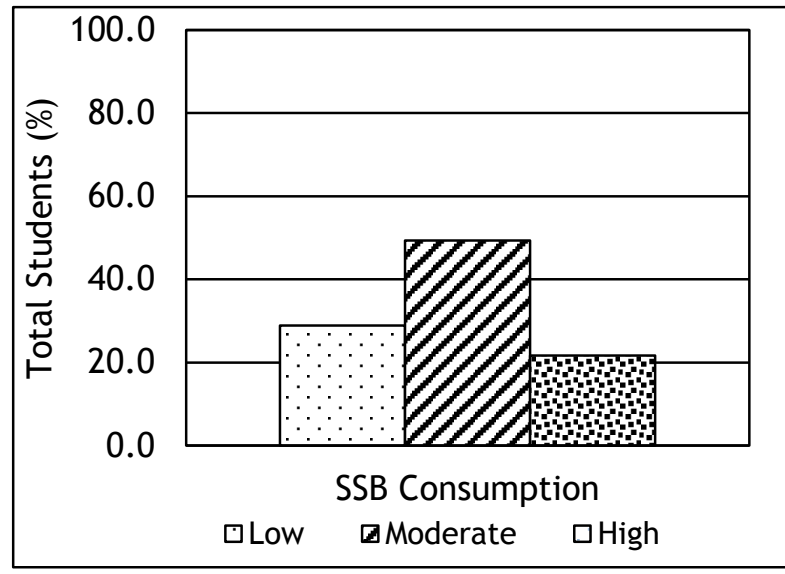

Figure 1: Pattern of SSB consumption among students on the average days

Table 5: Association between SSB consumption and BMI of students $(n=350)$

\begin{tabular}{cccccc}
\hline \multirow{2}{*}{$\begin{array}{c}\text { SSB Consumption } \\
(\mathrm{mL} / \text { day) }\end{array}$} & \multicolumn{5}{c}{$\begin{array}{c}\text { BMI, } \mathbf{n}(\%) \\
\text { kg/m }\end{array}$} \\
\cline { 2 - 5 } P-value $^{\mathrm{a}}$ \\
\cline { 2 - 5 } & Under-weight & Normal & Overweight & Obese & \\
\hline Low & $25(7.1)$ & $57(16.3)$ & $14(4.0)$ & $5(1.4)$ \\
Moderate & $31(8.9)$ & $100(28.6)$ & $32(9.1)$ & $10(2.9)$ & \multirow{2}{*}{$0.014^{*}$} \\
High & $5(1.4)$ & $41(11.7)$ & $22(6.3)$ & $8(2.3)$ & \\
\hline
\end{tabular}

a Chi-square test was applied.

*Significant difference at $p<0.05$

\section{DISCUSSION}

\section{Pattern of beverage intake of students}

Consumption of SSB has been increasing over the past few years as sweetened beverage production companies have increased their sales. The availability and attainable price of these beverages makes it tempting for consumers to purchase. Being enrolled in a university or any higher-level education institutions, students experience several social and environmental changes. These changes involve increased independence in daily living and decision making in all domains including health ${ }^{15}$. This study investigated SSB consumption among university students in Kuala Nerus. It was found that on the average days, $71.1 \%$ of the respondents consumed more than one cup daily. Similarly, Norliza et al. ${ }^{16}$ conducted a study among 401 university students in Selangor where the prevalence of intake of more than one cup of SSB on the average days was $89.3 \%$. This shows that a higher percentage of university students in Selangor consumed SSB more than the students in Terengganu, which might be due to the wider variety of SSBs in Selangor, which may be difficult or rare to find in Terengganu.

Among the students in this study, there was no limitation to gender when it comes to SSB consumption. Despite the differences in preferences of SSBs between genders, this study found that both male and female students preferred sweetened tea among the SSBs. A survey was conducted on Malaysian adults to discover the types of common beverage consumed daily and it showed that about $60 \%$ of respondents chose sweetened tea and coffee ${ }^{17}$. This indicates that the most preferred SSB among Malaysian citizen is sweetened tea. However, in contrast to this, a similar study conducted on 42 university students in Pahang found that the most chosen SSB was cordial or sweetened fruit-flavoured drinks $^{18}$. Although both genders consumed these SSBs in different amounts, the differences between genders in types of SSB consumption and the settings in which these were consumed have important implications to develop effective interventions targeted at this population. Sweetened tea consumptions in Malaysia are often sweetened by either sugar or sweetened condensed milk. Condensed milk is derived from cow's milk in which water has been removed, with added sugar and palm oil, making its content higher in sugar and fat while providing little to no protein. In Asia, it is the preferred milk, as compared to regular fresh milk, to be added to coffee or tea for better taste, such as teh tarik ${ }^{19}$.

Another reason for the high consumption of sweetened tea among these students was likely due to the rising trend of bubble teas. Bubble teas are tea-based beverages shaken with ice to create a foamy layer on top of the drink, which requires a significant amount of sugar, and chewy tapioca balls are added. Tapioca balls are made from tapioca, a type of starch. However, in Malaysia, more sugar is added in the making process of these tapioca balls to give the beverages a more chewy and sweet taste. These beverages are often consumed by the younger generation as they are more prone to social or peer influences, which are 
unlimited, even to university students. Furthermore, it was observed that there were a few beverage stalls at the cafeteria near the students' hostel. One of the many reasons why these students' SSB intake reached 2 cups/day or more was likely contributed as part of their lunch and/or dinner due to their tendency to consume sugary drinks while having main meals. A study by Nik Shanita et al. ${ }^{20}$ concluded that SSB intake among students was higher during main meals compared to snacking time.

\section{Association between SSB consumption and BMI}

Sugar-sweetened beverages contain one or a combination of two or more sweeteners which provide additional calories to an individual's diet. Excessive intake of these beverages is detrimental to our health as they contribute additional calories and if intake of excess sugar on a daily basis is prolonged, it can lead to weight gain which results in obesity ${ }^{21}$. The main compound in sugar is glucose which a simple sugar found in carbohydrates. An important function of glucose in the human body is to provide energy, whereas excess glucose is stored primarily in the liver for later energy use. However, because of limited storage, any glucose that is consumed beyond the storage capacity are converted to and stored as $\mathrm{fat}^{22}$. Hence, a higher SSB consumption with little energy spent will cause a higher fat storage in the body, leading to weight gain, as well as increased BMI. There is substantial evidence to suggest that the relationship between $\mathrm{BMI}$ and body fat percentage is dependent upon other factors such as race or ethnicity, body build and level of physical activity ${ }^{23}$. The findings of this present study indicate that SSB consumption of these students is closely linked to their BMI. It was found that there was a significant association between SSB consumption with different BMI categories. These results indicate that students with a higher SSB consumption have a higher BMI than those who consumed less SSBs. This was also supported by a study done on the body weight changes among postgraduate students at Universiti Sultan Zainal Abidin (UniSZA), Terengganu concluded that the most significant factors associated with body weight gains were the sociodemographic (female and art students) and eating behaviours ${ }^{24}$. This implies that the more SSBs they consumed, the more fat they store, hence, leading to an increased body weight which results in an increased BMI. The finding from this study is found to have similar results with several previous studies. For example, Mozaffarian et al. ${ }^{25}$ reported that among 120,000 men and women, those who increased their soft drink consumption by one 12-ounce serving per day ( $360 \mathrm{~g} / \mathrm{d}$ ) gained more weight over time (on average: an extra $0.5 \mathrm{~kg}$ every 4 years) than people who did not change their intake. Moreover, a report by Basu et al. ${ }^{26}$ stated that a $1 \%$ rise in soft drink consumption was associated with an additional 4.8 overweight adults per 100, and 2.3 obese adults per 100 . There have been several previous attempts aimed at reducing SSB consumption among consumers to reduce the prevalence of overweight and obesity, as well as the risk of other non-communicable diseases in Malaysia. An introduction of an excise tax of 40 cents per litre on sugary beverages and the introduction of a healthy school breakfast programme have been carried out since April 2019 to address obesity. However, such programmes alone may not be sufficient to tackle the growing rate of obesity due to several other factors that contribute to SSB consumption such as those mentioned earlier.

\section{CONCLUSION}

Sugar-sweetened beverages consumption may differ in types and amounts of consumption between male and female university students, however both genders preferred sweetened tea as their choice of SSB. Furthermore, this study discovered an association between SSB consumption and BMI of the students in which a higher SSB consumption shows a higher BMI. Thus, this study provides opportunities for health promotion interventions targeted at university students since the significance of environment and social settings in which types and amount of SSB consumed are recognized. It must be acknowledged that there are several limitations in this study. Firstly, this study was conducted among students that came from various states, however participants in this study were majorly from Malay ethnic. Due to this, there are lesser number of people from other ethnicities, such as Chinese and Indian, thus comparison between ethnicities was restricted. Another limitation is that the beverage intake questionnaire in this study does not cover all types of SSBs and that the exact measurement of how much SSBs was consumed may have contributed to underreporting. Thus, further suggestions to attain more accurate results should include methods in which all types of SSB's and their exact consumption are measured appropriately, as well as the settings in which they are consumed to understand these students' SSB consumption better.

\section{REFERENCES}

1. Lim KG. A review of adult obesity research in Malaysia. Med J Malaysia 2016; 71(1):1-19.

2. WHO:Obesity and Overweight. Fact Sheet.

http://www. who.int/en/newsroom/fact-sheets/detail/obesityand-overweight. National Health and Morbidity Survey 2015:Malaysian Adult Nutrition Survey (accessed 4 May 2019).

3. Gan WY, Mohamed SF, Law LS. Unhealthy lifestyle associated with 
higher intake of sugar-sweetened beverages among Malaysian schoolaged adolescents. International Journal of environmental research and public health 2019; 16(15):2785.

4. Bundrick SC, Thearle MS, Venti CA, et al. Soda consumption during ad libitum food intake predicts weight change. J Acad Nutr Diet. 2014; 114(3):444-449.

5. Martin-Calvo N, Martinez-Gonzalez MA, Bes-Rastrollo M, et al. Sugarsweetened carbonated beverage consumption and childhood/adolescent obesity: A case-control study. Public Health Nutr 2014; 17(10):2185-2193.

6. Nanney MS, Lytle LA, Farbakhsh K et al. Weight and weight-related behaviours among 2-year college students. J Am Coll Health 2015; 63:221-229.

7. Dehdari T, Mergen T. A survey of factors associated with soft drink consumption among secondary school students in Farooj city. 2010. Journal of Jahrom University of Medical Sciences 2012; 9(4):33-39.

8. Deliens T, Clarys P, De Bourdeaudhuij I, et al. Correlates of university students' soft and energy drink consumption according to gender and residency. Nutrients 2015; 7:65506566.

9. Lua PL, Wan Putri Elena WD, Mohd Razif S. Nutrition quality of life among female-majority malay undergraduate students of health sciences. Malays J Med Sci 2012; 19(4):37-49.

10. Mona M, Abeer S, Fatema AA, Fatema A. Health effects of soda drinking in adolescent girls in the United Arab Emirates. Journal of critical care 2008; 23(3):434-440.

11. Mahmood M, Saleh A, Al Alawi F et al. Health effects of soda drinking in adolescent girls in the United Arab Emirates. Journal of Critical Care 2008; 23(3):434-440.

12. Munt AE, Partridge R, Allman-Farinelli M. The barriers and enablers of healthy eating among young adults: a missing piece of the obesity puzzle: A scoping review. Obesity Reviews 2017; 18(1):1-17.
13. Hedrick VE, Jyoti Savla, Dana LC, et al. Development of a brief questionnaire to assess habitual beverage intake (BEVQ-15): sugarsweetened beverages and total beverage energy intake. J Acad Nutr Diet. 2012; 112(6):840-849.

14. WHO Expert Consultation. Appropriate body-mass index for Asian populations and its implications for policy and intervention strategies. Lancet 2004; 363:157-163.

15. Gillen MM, Lefkowitz ES. Gender and racial/ethnic differences in body image development among college students. Body Image 2012; 9(1):126-130.

16. Norliza A, Muhammad Afiq MZ, Nur Azilah A, et al. Prevalence and factors associated with sugar-sweetened beverage intake among undergraduate students in a public university in Malaysia. Pakistan Journal of Nutrition 2019; 18:354363.

17. Regular Beverage Consumption in Malaysia Statistics. Statista Research Department.

https: / / www.statista.com/statistics /561175/malaysia-regular-beverageconsumption 2016. (accessed 19 May 2019).

18. Hamirudin $\mathrm{AH}$, Zahari NA, Badarudin NE. (2018). Consumption of sugarsweetened beverages among International Islamic University Malaysia (IIUM), Kuantan students. International Journal of Allied Health Sciences 2018; 2(3):499-506.

19. Prateek S, Patel H, Patel A Ashok. In: Chandan, Ramesh C, Kilara A, Shah NP, eds. Dairy Processing and Quality Assurance. John Wiley \& Sons, Ltd. 2015:310-332.

20. Nik Shanita S, Norimah AK, Abu Hanifah S. Development and validation of a Food Frequency Questionnaire (FFQ) for assessing sugar consumption among adults in Klang Valley, Malaysia. Malaysian journal of nutrition 2012; 18(3):283293.

21. Malik VS, Popkin BM, Bray GA, et al. Sugar-sweetened beverages, obesity, type 2 diabetes mellitus, and 
cardiovascular disease risk. Circulation 2010; 121:1356-1364.

22. Utiger RD. Insulin. Encyclopaedia Britannica 2019. https://www.britannica.com/scienc e/insulin-like-growth-factor (accessed 23 Sept 2019).

23. Yusoff NAM, Ganeson S, Ismail KF, et al. Physical activity level among undergraduate students in Terengganu, Malaysia using pedometer. J Fundam Appl Sci 2018; 10(1s):512-522.

24. Hadizaabdullahi AB, Mohd Razif S, Sharifah Wajihah Wafa SSTW. Weight Status, dietary intake and eating behaviour of Nigerian postgraduate students in UniSZA, Malaysia. Malaysian Journal of Public Health Medicine 2016; 16(3):45-51.

25. Mozaffarian D, Hao T, Rimm EB, et al. Changes in diet and lifestyle and longterm weight gain in women and men. $N$ Engl J Med 2011; 364(25):23922404.

26. Basu S, Yoffe $P$, Hills $N$, et al. The relationship of sugar to populationlevel diabetes revalence: an economic analysis of repeated crosssectional data. PLoS ONE 2013; 8(2):e57873. 